3. Shimosato Y, Mukai K. Tumors of the mediastinum. In: Rosai J, Sobin LH, editors. Atlas of tumor pathology. No. 21. Washington, DC: Armed Forces Institute of Pathology; 1997. p. 40.
4. Bailey PV, Tracy T, Connors RH, deMello D, Lewis JE, Weber TR. Congenital bronchopulmonary malformations: diagnostic and therapeutic considerations. J Thorac Cardiovasc Surg. 1990;99:597-603.

\title{
Mediastinal growing teratoma syndrome after cisplatin-based chemotherapy and radiotherapy for intracranial germinoma
}

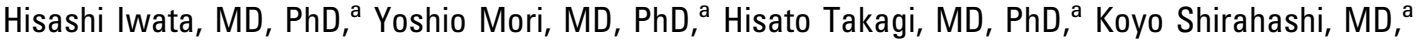 \\ J̧un Shinoda, MD, PhD, ${ }^{b}$ Kuniyasu Shimokawa, MD, PhD, ${ }^{c}$ and Hajime Hirose, MD, PhD, ${ }^{a}$ Gifu, Japan
}

$\mathrm{N}$ onseminomatous germ cell tumor (NSGCT) has been treated with cisplatin-based chemotherapeutic regimens. In cases of good response of tumor to chemotherapy, elevated tumor markers such as alpha-fetoprotein (AFP) and human chorionic gonadotropin (hCG) return to normal with tumor shrinkage. However, a small proportion of cases demonstrate tumor growth during or after the treatment. This distinctive situation was first described for testicular NSGCT by Logothetis and colleagues ${ }^{1}$ and was designated the growing teratoma syndrome (GTS). In this report we describe GTS of the mediastinum after cisplatin-based chemotherapy and radiotherapy for intracranial germ cell tumor.

\section{Clinical Summary}

A 20-year-old man with a rapidly growing mediastinal tumor was referred to our department. One month before, tumors in the pineal and the suprasellar regions had been found, with bitemporal hemianopia. Results of routine blood chemistry and coagulation studies were normal; however, serum AFP and hCG were increased to 447 $\mathrm{ng} / \mathrm{mL}$ and $240 \mathrm{ng} / \mathrm{ml}$, respectively. Serum carcinoembryonic antigen level was normal. The patient underwent partial resection of the suprasellar lesion for pathologic diagnosis. The pathologic diagnosis in the lesion was germinoma. Thereafter, the patient underwent chemotherapy consisting of ifosfamide, cisplatin, and etoposide followed by 20 Gy local irradiation. The intracranial lesions completely disappeared. Serum AFP and hCG were decreased to within normal limits.

After these therapies, a chest roentgenogram accidentally disclosed a mass located in the mediastinum. Chest computed tomog-

From First Department of Surgery, ${ }^{a}$ Department of Neurosurgery, ${ }^{\mathrm{b}}$ and Department of Laboratory Medicine, ${ }^{\mathrm{c}}$ Gifu University School of Medicine, Gifu, Japan.

Received for publication June 19, 2003; accepted for publication July 10, 2003.

Address for reprints: Hisashi Iwata, MD, PhD, First Department of Surgery, Gifu University School of Medicine, 40 Tsukasa-machi, Gifu City, Gifu 5008705, Japan (E-mail: ihisashi@cc.gifu-u.ac.jp).

J Thorac Cardiovasc Surg 2004;127:291-3

$0022-5223 / \$ 30.00$

Copyright $\odot 2004$ by The American Association for Thoracic Surgery

doi:10.1016/S0022-5223(03)01300-X raphy showed a round and lobulated mass in the anterosuperior mediastinum. The size of the mass rapidly increased (Figure 1). Tumor doubling time was calculated at 34.3 days. The tumor showed no response to $20 \mathrm{~Gy}$ irradiation. Gallium scintigraphy showed a slightly intense mediastinal enhancement region and no other lesion outside the chest. Histologic examination of a percutaneous needle biopsy specimen showed necrotic and fibrous connective tissue.

A median sternotomy was performed. The tumor was encapsulated in the thymic tissue. A complete resection was performed with negative margins.

On pathologic examination, the specimen of the mediastinal tumor was characteristic of mature teratoma. The tumor consisted of mature squamous epithelium with immature glandular structures. Immature structure tested immunohistochemically positive for carcinoembryonic antigen and keratin but negative for AFP and hCG (Figure 2, A). However, the immature component was less than $10 \%$ of the tumor. Retrospective pathologic examination in the intracranial lesion resected before chemoradiotherapy revealed pure germinoma with negative results of immunohistochemical testing for AFP and hCG (Figure 2, B).

The postoperative course was uneventful. At 8-month followup, the patient is doing well with no evidence of disease.

\section{Discussion}

Mediastinal germ cell tumors are heterogeneous groups of benign and malignant neoplasm thought to originate from primitive germ cells misplaced in the mediastinum. ${ }^{2}$ Teratoma, the most common mediastinal germ cell tumor, is classified as either mature teratoma, well-differentiated histologically and containing less than $10 \%$ fetal tissue, or immature teratoma, containing more than $10 \%$ fetal tissue. ${ }^{3}$

The definition of GTS encompasses three criteria: first, normalization of previously elevated serum tumor marker AFP or hCG, second, an increase in tumor size during or after chemotherapy given for NSGCT, and third, the absence of any NSGCT component other than mature teratoma in the tumor resected. ${ }^{1}$ The incidence of GTS among patients with metastatic NSGCT is between $1.9 \%$ and $7.6 \% .^{1,4}$

In our case, serum AFP and hCG levels had returned to normal after the chemoradiotherapy for intracranial lesions. The residual mediastinal tumor was disclosed accidentally and grew after chemoradiotherapy. The specimen of the mediastinal tumor was his- 


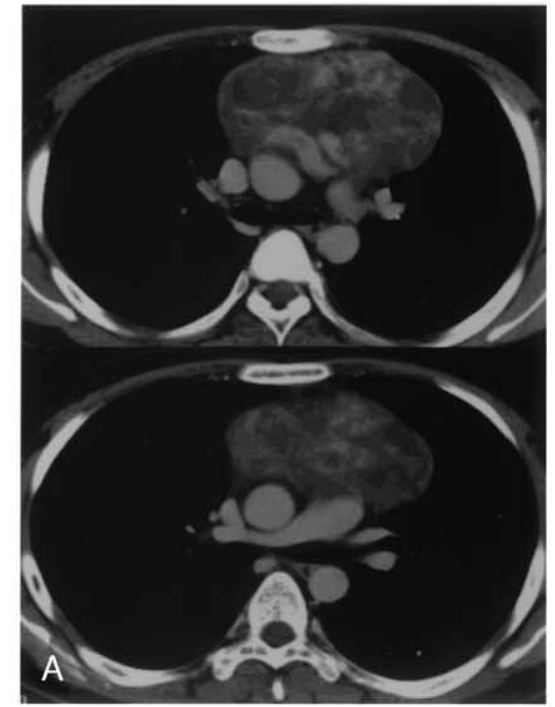

2002.8.30

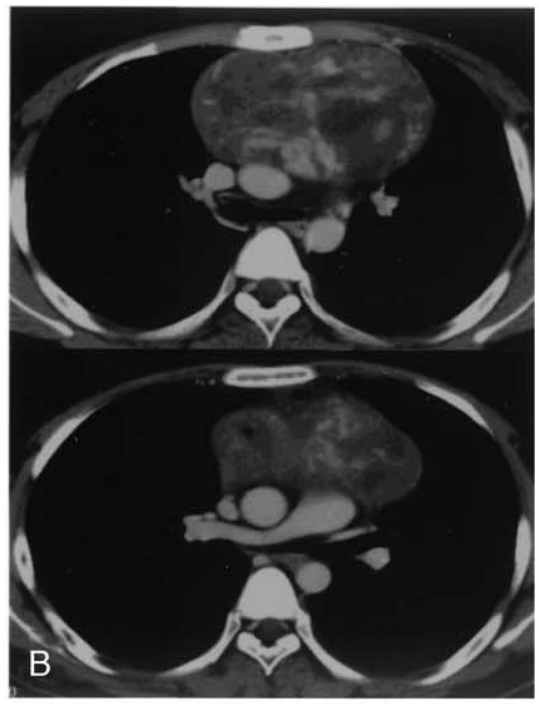

2002.9.12

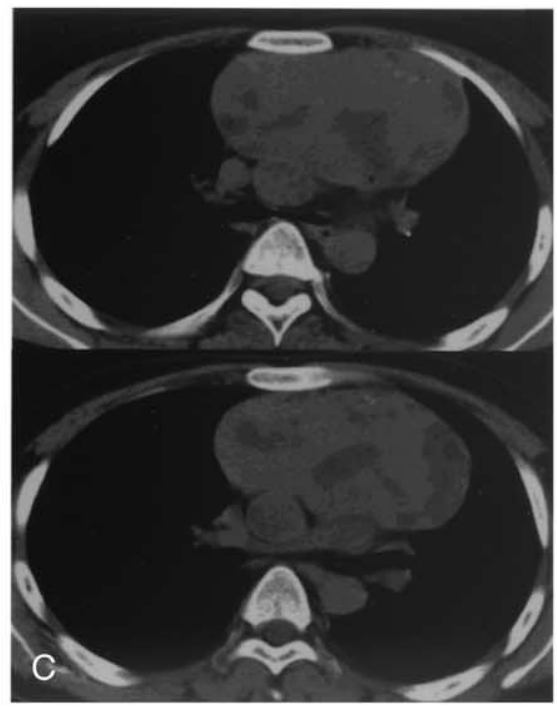

2002.9.18

Figure 1. Rapid-growing mediastinal tumor. Tumor doubling time was 34.3 days. A, Chest computed tomographic findings at admission to our department; B, 12 days after admission; C,19 days after admission.
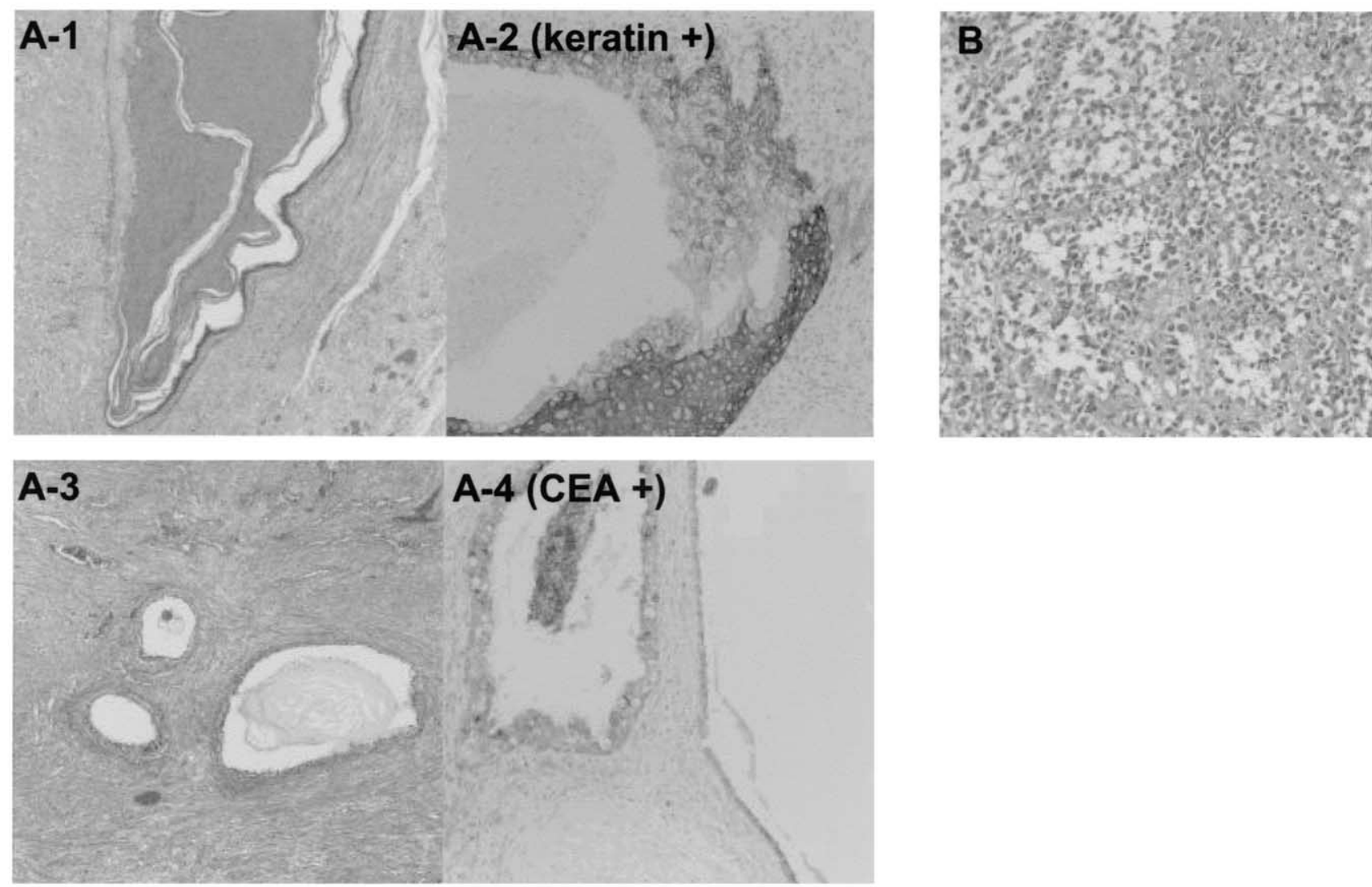

Figure 2. Tumor consists of mature squamous epithelium with immature glandular structures (A-1). Mature squamous epithelium stains positively for keratin (A-2). Immature glandular structure (A-3) is less than $10 \%$ in the tumor and positive for carcinoembryonic antigen (A-4) but stains negatively for AFP and hCG. Intracranial tumor partially resected before chemoradiotherapy (B) was pure germinoma and negative for AFP and hCG. 
tologically determined to be mature teratoma. However, the pathological findings of the needle-biopsy specimen after chemoradiotherapy included necrotic and fibrous connective tissue. These results may suggest the additional existence of an NSGCT component other than teratoma in our case, which could secrete AFP or hCG and disappeared after the therapies.

With respect to primary mediastinal GTS, Chen and colleagues ${ }^{5}$ first reported the increasing immature teratoma as GTS. Afifi and associates ${ }^{6}$ stated that Chen and colleagues' case did not fulfill the criteria of GTS because the AFP level did not return to normal and mature teratoma was not documented after resection. Iyoda and coworkers ${ }^{7}$ noted that immature component was very small in their case of GTS and reviewed 4 cases of primary mediastinal GTS from the previous reports. Our case represents the 5th reported case of primary mediastinal GTS.

Primary intracranial germ cell tumors are rare malignancies. The tumors of the pineal gland comprise germinoma (45\%), NSGCT (16\%), pineal parenchymal gliomas (15\%), and other lipomas, cysts, metastases, and meningioma (7\%). O'Callaghan and colleagues ${ }^{8}$ reported intracranial GTS in an NSGCT of the pineal gland.

The biopsy specimen of the intracranial tumor in our case represented pure germinoma histologically because test results were negative for AFP and hCG after chemoradiotherapy. It is unclear whether the intracranial tumor was a metastatic lesion from the mediastinal heterogeneous tumors. We regard our case as a primarily double cancer case with intracranial and mediastinal germ cell tumors, because these tumors arose in the likely sites each as primary germ cell tumor rather than as a metastasis.

Regarding treatment for NSGCT, surgical resection of a residual mass is usually performed only in patients with normal levels of tumor markers. Previous reports of primary mediastinal GTS have noted that complete resection of residual mass after chemo- therapy or chemoradiotherapy could be successful with good prognosis. ${ }^{5-7,10}$

Andre and associates ${ }^{9}$ reported that 5-year overall survival and progression-free survival of GTS are $90 \%$ and $73 \%$, respectively. In the reported 4 cases of primary mediastinal GTS, there was 1 case with local recurrence 5 months after the complete resection. ${ }^{10}$ The other cases had no recurrence for 3,24, and 27, months after the operation. ${ }^{5-7}$

\section{References}

1. Logothetis CJ, Samuels ML, Trindade A, Johnson DE. The growing teratoma syndrome. Cancer. 1982;50:1629-35.

2. Strollo DC, Rosado de Christenson ML, Jett JR. Primary mediastinal tumors. Part 1: tumors of the anterior mediastinum. Chest. 1997;112: 511-22.

3. Gonzalez-Crussi F. Extragonadal teratomas. Atlas of tumor pathology. Washington, DC: Armed Forces Institute of Pathology; 1982.

4. Jeffery GM, Theaker JM, Lee AH, Blaquiere RM, Smart CJ, Mead GM. The growing teratoma syndrome. Br J Urol. 1991;67:195-202.

5. Chen LT, Chen CL, Hwang WS. The growing teratoma syndrome. A case of primary mediastinal nonseminomatous germ cell tumor treated with chemotherapy and radiotherapy. Chest. 1990;98:231-3.

6. Afifi HY, Bosl GJ, Burt ME. Mediastinal growing teratoma syndrome. Ann Thorac Surg. 1997;64:359-62.

7. Iyoda A, Hiroshima K, Yusa T, Toyozaki T, Fujisawa T, Ohwada H. The primary mediastinal growing teratoma syndrome. Anticancer Res. 2000;20:3723-6.

8. O'Callaghan AM, Katapodis O, Ellison DW, Theaker JM, Mead GM. The growing teratoma syndrome in a nongerminomatous germ cell tumor of the pineal gland: a case report and review. Cancer. 1997 $1 ; 80: 942-7$

9. Andre F, Fizazi K, Culine S, Droz J, Taupin P, Lhomme C, et al. The growing teratoma syndrome: results of therapy and long-term follow-up of 33 patients. Eur J Cancer. 2000;36:1389-94.

10. Massard G, Eichler F, Gasser B, Bergerat JP, Wihlm JM. Recurrence of the mediastinal growing teratoma syndrome. Ann Thorac Surg. 1998;66:605-6. 